\title{
Influence of marginal fit and cement types on microleakage of all-ceramic crown systems
}

\author{
Ece Yüksel(a) \\ Ali Zaimoğlu(a) \\ (a) Department of Prosthodontics, Faculty of \\ Dentistry, Ankara University, Ankara, Turkey.
}

\begin{abstract}
The purpose of this study was to evaluate the effects of both marginal fit and cementing with different luting agents on the microleakage of all-ceramic crown systems. Thirty-six extracted upper central incisors were prepared for full-coverage crowns and were divided into three groups. Group 1: CAD/CAM-fabricated $\mathrm{ZrO}_{2}$, Group 2: Heatpressed lithium-disilicate, and Group 3: Cast Cr-Co copings as the control group. Copings were made following standard techniques, and groups were assigned cementation with either self-adhesive resin cement (A) or glass-ionomer luting cement (B). The specimens were subjected to thermocycling, immersed in basic fuchsin solution, sectioned mesiodistally and buccolingually. The surface of each section was digitally photographed under a stereomicroscope. Microleakage was scored using a five-point scale, and the marginal gap was measured using image analysis software. Data were statistically analyzed using 2-way ANOVA, Kruskal-Wallis, and Mann-Whitney $U$ tests $(\alpha: 0.05)$. The marginal discrepancy of each group was $82.7 \pm 7 \mu \mathrm{m}, 92.6 \pm 4 \mu \mathrm{m}$ and $96.5 \pm 7 \mu \mathrm{m}$ respectively. Group 1 showed significantly smaller gaps than Group 3 $(\mathrm{P}=0.042)$. Self-adhesive resin cement $(\mathrm{A})$ showed a lower level of microleakage than glass-ionomer luting cement $(\mathrm{B})$ in all groups $(\mathrm{P}=0.029)$. Microleakage scores of ' 0 ' were $83 \%$ for $1 \mathrm{~A}, 50 \%$ for $1 \mathrm{~B}, 50 \%$ for $2 \mathrm{~A}$, $16 \%$ for $2 \mathrm{~B}, 33 \%$ for $3 \mathrm{~A}$ and none for 3B. Marginal discrepancy and cement type both had significant effects on microleakage. Lower levels of microleakage were recorded with self-adhesive resin cement, while CAD/ CAM-fabricated $\mathrm{ZrO}_{2}$ copings showed smaller marginal discrepancy and less microleakage in comparison to cast Cr-Co.
\end{abstract}

Descriptors: Dental leakage; Dental cements; Dental marginal adaptation; Crowns.

\section{Introduction}

Microleakage is classically defined as the diffusion of substances, such as bacteria, oral fluids, molecules and/or ions, into a fluid-filled gap or a structural defect that is naturally present or that occurs between restorative materials and tooth structure. ${ }^{1}$ The amount of microleakage depends on a number of factors. Complex interactions between variables related to dental restoration, luting agents and tooth structures are known to influence the amount of microleakage. ${ }^{2}$

Metal-ceramic crowns are an example of full-coverage dental res-
Received for publication on Dec 14, 2010 Accepted for publication on Mar 30, 2011 
toration that has been widely used since the late 1950s. Although metal-ceramic crowns possess high strength, the increasing interest in more aesthetically pleasing restorations over the last few years has stimulated the development of all-ceramic crown restorations. $^{3}$

All-ceramic crown systems may be fabricated using different techniques. One of these techniques is the heat-press, which is similar to the method of metal-ceramic crowns, as that also utilizes the lostwax method. ${ }^{4,5}$ The difference of the heat-press is that it involves the use of a special porcelain furnace with a pneumatic ram, which presses the ceramic material into the mold at high temperatures under vacuum. The system produces a high-strength core, consisting primarily of lithium-disilicate glass. ${ }^{6} \mathrm{An}-$ other technique is the computer-aided design and manufacturing (CAD/CAM) system, which focuses on precise and consistent manufacturing of $\mathrm{ZrO}_{2}$ ceramics with high strength and toughness. ${ }^{7}$

The different materials and applied techniques in the manufacturing of crown systems have significant effects on the strength of the final restoration as well as the marginal fit. All-ceramic restorations must satisfy the clinical requirements in these respects to be considered successful. ${ }^{6}$ Minimizing the marginal gap is also necessary because an increase in the marginal gap results in an increase in cement dissolution, thus increasing the potential for microleakage. ${ }^{5,8}$

Luting agents' sealing ability and resistance to the varying stresses are also important factors that influence the extent of leakage. ${ }^{9}$ Lyons et al. ${ }^{10}$ showed that glass-ionomer and resin cements have increasingly been used as luting agents, principally because of their ability to bond to tooth structure and, in some instances, to restorations as well.

The properties of glass ionomer cement, such as its physicochemical bond to dentin and enamel, reduced film thickness, minimal thermal expansion and hydrophilic qualities with low solubility, make it popular for cementation. In addition, glass ionomer cements contain leachable calcium fluoride that provide a cariostatic advantage. ${ }^{11}$

Resin luting systems are also recommended for the cementation of all-ceramic systems. ${ }^{9}$ Bernal et al. ${ }^{12}$ reported that significantly stronger all-ceramic crowns are achievable by luting with adhesive resin cements. However, the multistep application technique has been reported to be complex and sensitive, which can influence bonding effectiveness. ${ }^{13}$ Therefore, a new type of luting material, called selfadhesive cement, that does not require any pretreatment of the tooth surface has been developed. This material combines the favorable properties of conventional (zinc phosphate, glass ionomer, and polycarboxylate) and resin cements. ${ }^{13}$

There have been many studies on the effects of luting agents on microleakage, ${ }^{1,9-11}$ and on the evaluation of marginal fit of different crown systems. ${ }^{5-8,14}$ However, the number of studies that examine the combined effects of luting agents and marginal fit of crown systems on microleakage are very few. ${ }^{2,3,9}$ Therefore, the purpose of this in vitro study was to determine and evaluate the effect on microleakage, if any, of the marginal fit of two different allceramic crown systems using two different luting agents. Considering all of the factors mentioned in this introduction, the study hypothesis was that there would be a distinctive relation between both the marginal fit values and the luting agents on the level of microleakage.

The null hypothesis is two-fold:

1. there is no strong correlation between marginal fit differences of all-ceramic systems and microleakage, and

2. there are no differences in the microleakage values among the luting agents tested in this research.

\section{Methodology}

This study was submitted and approved by the Research Ethics Committee of the University of Ankara, Faculty of Dentistry. Thirty-six extracted, similarly sized upper central incisors with coronal lengths of approximately $9-10 \mathrm{~mm}$ were prepared for full-coverage crowns by a single operator. Preparations were completed at the dentin level of the cemento-enamel junction with a chamfer finish line of $1.2 \mathrm{~mm}$. The height of the preparations was $7 \mathrm{~mm}$ with a convergence angle of 6 degrees (Diamond bur number 3215, KG Sorensen, Sao Paulo, Brazil). Pre- 
pared teeth were divided into three groups $(n=12)$. Teeth in Group 1 were prepared to receive $\mathrm{ZrO}_{2}$ copings using the CAD/CAM method (3M ESPE Lava, St. Paul, USA); Group 2 was prepared for heat-pressed lithium-disilicate copings (IPS e.max Press, Ivoclar Vivadent, Schaan, Liechtenstein), and Group 3 was prepared for cast Cr-Co frameworks (Wirobond C, BEGO, Bremen, Germany) as the control group. After impressions were made with polyether impression material (Impregum F, 3M ESPE, Seefeld, Germany), the copings were made following standard techniques. Each group was divided into two subgroups, (A) and (B), using cementation with self-adhesive resin cement (RelyX U100, 3M ESPE, St. Paul, USA) and glass-ionomer luting cement (KETAC CEM, 3M ESPE, St. Paul, USA), respectively. After 24 hours of storage in distilled water at $37{ }^{\circ} \mathrm{C}$, all teeth were subjected to 1,000 thermal cycles (Thermal Cycle, Nüve, Ankara, Turkey) between $5^{\circ}$ and $55^{\circ} \mathrm{C}$ using a dwell time of 30 seconds. The roots of the teeth were coated with nail polish (Goldenrose, Istanbul, Turkey) up to $1 \mathrm{~mm}$ below the restoration margins and immersed in $0.5 \%$ basic fuchsin dye (Structure Probe, Inc., West Chester, USA) for 24 hours. Following removal from the solution, the teeth were rinsed under tap water and embedded in autopolymerizing acrylic resin (Orthocryl EQ, Dentaurum, Ispringen, Germany). Each tooth was vertically sectioned mesiodistally and buccolingually with a water-cooled diamond disc (Mikrocut, Metkom, Bursa, Turkey). Four specimens were made from each tooth. For each specimen, each of the four sectioned surfaces was digitally photographed at x50 under a stereomicroscope (Carl Zeiss AG, Oberkochen, Germany), and the data was transferred to a personal computer. For each specimen, marginal gaps were measured using image analysis software (KS400 Image for Windows, Carl Zeiss AG), and the percentage of the microleakage was scored as follows:

- $0=$ no leakage,

- 1 = leakage up to one third of the axial wall,

- 2 = leakage up to two thirds of the axial wall,

- 3 = leakage along the entire length of the axial wall,

- 4 = leakage extending onto the occlusal aspect. ${ }^{3}$
The distribution of continuous variables was investigated using the Shapiro-Wilk test. Marginal fit values are shown as mean \pm standard deviation, while leakage scores are represented as frequency distributions.

Marginal fit values according to fabrication techniques and cement types were assessed by two-way ANOVA. Differences arising from fabrication techniques in terms of leakage scores were evaluated by Kruskal-Wallis tests, whereas the difference of leakage scores arising from cement types was evaluated by Mann-Whitney U tests. Results with $p<0.05$ were considered statistically significant.

\section{Results}

The mean marginal discrepancy values were:

- Group 1, $82.7 \pm 9.91 \mu \mathrm{m}$;

- Group 2, $92.6 \pm 9.53 \mu \mathrm{m}$; and

- Group 3, $96.5 \pm 11.10 \mu \mathrm{m}$.

Group 1 showed significantly smaller gaps than Group 3 ( $p=0.042$ ). There was no significant difference between Groups 2 and 3 ( $p=0.536$ ) (Graph 1).

Microleakage scores recorded in this study varied from $0-2$. There was a significant association between cement type and microleakage score. Cement A showed a lower level of microleakage than cement $\mathrm{B}$ in all groups $(p=0.029)$.

The rates of microleakage scores of ' 0 ' by Group and cement type were $83 \%$ for $1 \mathrm{~A}, 50 \%$ for $1 \mathrm{~B}$, $50 \%$ for $2 \mathrm{~A}, 16 \%$ for $2 \mathrm{~B}, 33 \%$ for $3 \mathrm{~A}$ and none for $3 \mathrm{~B}$. Group $1 \mathrm{~A}$ had the lowest amount of microleakage, and the highest microleakage was observed in Groups 2B and 3B $(p<0.026)$ (Table 1).

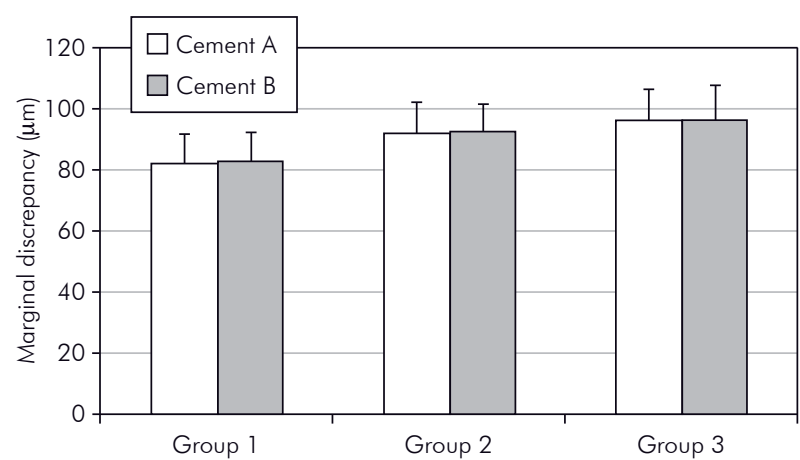

Graph 1 - Marginal discrepancy values of each group. 
Table 1 - Group distribution of microleakage scores.

\begin{tabular}{c|c|c|c}
\hline Groups & Score 0 & Score 1 & Score 2 \\
\hline $1 \mathrm{~A}$ & 5 & 1 & - \\
\hline $1 \mathrm{~B}$ & 3 & 1 & 2 \\
\hline $2 \mathrm{~A}$ & 3 & 2 & 1 \\
\hline $2 \mathrm{~B}$ & 1 & 2 & 3 \\
\hline $3 \mathrm{~A}$ & 2 & 2 & 2 \\
\hline $3 \mathrm{~B}$ & - & 2 & 4 \\
\hline
\end{tabular}

\section{Discussion}

The data obtained in this study show statistically significant differences in microleakage levels for varying marginal fit values and different luting agents, thus supporting the study hypothesis (and rejecting the null hypothesis) that there is an influence of the marginal fit values and the luting agent on the level of microleakage.

Marginal discrepancies in the range of $100 \mu \mathrm{m}$ have been reported to be clinically acceptable with regard to longevity of a restoration. ${ }^{8}$ All the copings tested in this study were well within this limit. The present marginal discrepancy values of Cr-Co copings $(96.5 \pm 11.10 \mu \mathrm{m})$ showed similarity to those of previous studies, ${ }^{14,15}$ except for the results obtained by Gonzalo et al., ${ }^{16}$ who found lower marginal discrepancy values. Marginal gap values for lithiumdisilicate copings $(92.6 \pm 9.53 \mu \mathrm{m})$ were higher than the marginal discrepancy $(81 \pm 25 \mu \mathrm{m})$ reported by Goldin et al. ${ }^{14}$ The lowest marginal discrepancies were obtained for $\mathrm{ZrO}_{2}$ copings $(82.7 \pm 9.91 \mu \mathrm{m}$ ), which is in agreement with the findings of Gonzalo et al. ${ }^{17}$

It should be taken into consideration that the different manufacturing processes may affect the discrepancy results. ${ }^{17}$ An explanation of the noticeable difference between the marginal discrepancy of $\mathrm{ZrO}_{2}$ copings and that of Cr-Co copings is the precision of the CAD/CAM technique, which reduces marginal gap. ${ }^{16}$ This also supports the results obtained in our study.

The expansion and contraction properties of the various materials used in the fabrication of cast copings, combined with the complex fabrication steps of the casting process, makes achieving an accept- able fit of a cast coping considerably difficult. ${ }^{5,16}$ To reduce the effects of these factors on the results obtained in this study, similar-sized teeth and samesize burs were utilized, preparations were completed by a single operator, and the technique sensitivity of the dental technician was closely observed. Thus, we aimed to make the size and thicknesses of the copings as similar as possible.

The space required for the luting agent is enabled by die spacers in the casting process, whereas this space is digitally adjusted in the CAD/CAM method. It was previously found that adequate die spacing is an important factor for the accuracy of restoration margins. ${ }^{16}$ To eliminate the effect of this factor on marginal discrepancy, all copings in this study were fabricated with a die space of $50 \mu \mathrm{m}$.

The luting agents may also influence the marginal discrepancy values by elevating the crown after cementation. In the current study, the marginal discrepancy of the crowns cemented with glass ionomer cement was slightly greater than that of the crowns cemented with resin cement in all of the analyzed groups, but no significant differences were observed. This can be explained by the differences in viscosity of the cements. ${ }^{9,16,18}$

It is difficult to interpret the statistical results of the previous studies because of variations in the sample size, the measurements per specimen and the measurement methods used. ${ }^{6,7,16}$ There is no standardized method to measure the marginal fit. The most common methods are the cross-sectional view, the direct view of the crown on a die, the impression replica technique, and clinical examination. ${ }^{18}$ In the current study, the cross-section method was used to measure the marginal fit, which enables the measurement of cemented restorations. ${ }^{18}$ Ferrari et al. ${ }^{19}$ mentioned that the absolute marginal discrepancy appears to be better defined by the cross-section method when compared to direct viewing of the margins and thus easier to determine.

According to the cross-sectional views of the specimens, self-adhesive resin cement showed lower microleakage than glass-ionomer cement in all groups. This can be explained by the solubility of the cements, which plays an important role in providing a better seal. ${ }^{20}$ Water-soluble cements such as 
glass-ionomer deteriorate over time due to the deleterious effects of thermocycling. However, the insoluble resin cement absorbs water, which may help the relaxation of internal stresses caused by polymerization shrinkage. This also decreases the potential of interfacial failure of the resin cement during thermocycling. ${ }^{3}$

The adhesion of glass-ionomer cement is affected by the ionic and polar nature of the molecular interactions between the cement and the tooth substance. These mechanisms are only effective if close intermolecular contact is achieved between the cement and the tooth. The failure of glass-ionomer cements may be explained by the porosities that may appear during mixing, thus decreasing intermolecular contact between the cement and the tooth. Another possibility is the appearance of micro-cracks as a result of contraction during thermal cycling, which may produce stresses that exceed the cohesive and adhesive strength of the material. This can result in disruptions of the cement layer, allowing microleakage to occur. ${ }^{10,11}$

Rosentritt et al. ${ }^{21}$ concluded that the resin cements and the self-adhesive material show good marginal integrity and low microleakage, and the self-adhesive resin cements are showing potential promise as an easily applicable alternative to resin cements. Conversely, Albert and El-Mowafy ${ }^{3}$ mentioned that glass-ionomer and resin-modified glassionomer cements should be considered as alternatives to resin cement, because of the difference in the nature of dentinal adhesion, one being chemical (glass-ionomer) and the other micromechanical (resin).

Microleakage and marginal openings are important causes of fixed restoration failures. When crown type is taken into consideration, one of the reasons for high microleakage is the amount of marginal gap, the increase of which causes greater microleakage, because the amount of cement exposed to oral fluids depends on the extent of the marginal gap. ${ }^{3}$ Other factors, such as the mechanical properties of the luting cement and the adhesion between cement and tooth structure can also promote microleakage. Finally, lower bond strength of a dentin adhesive may also cause a greater amount of micro- leakage. ${ }^{10}$

There were some limitations in this study. Nonveneered single crown copings were investigated just as in Reich et al.,22 but the results would change by applying veneering porcelain. Although Hung et al..$^{23}$ demonstrated a significant negative effect of thermal cycling on marginal fit of crowns, no comparison was made on the effect of this process in the current study. However, Beschnidt and Strub ${ }^{24}$ mentioned that there was no significant effect of an aging procedure on the marginal fit. The clinical scenario was simulated as closely as possible, and each coping was evaluated as if it were to be placed intraorally, but intraoral environmental variables (such as temperature and humidity) were simulated for cementation. Another limitation in this study was the areas in which the microleakage occurred. It was stated that microleakage may occur on the cement-tooth interface as well as the cement-restoration interface. In a stressed situation, the weakest link breaks first, and it was indicated that the cement-tooth interface is the weakest link. ${ }^{10}$ This study did not differentiate where the microleakage occurred but rather focused on the extent of the microleakage itself. The method used cannot define or control the interface in which the microleakage occurs. Further studies are suggested to reveal, if any, the possible effects of the interface where microleakage occurs.

\section{Conclusion}

Within the limitations of this study, it was concluded that marginal discrepancy and cement type had significant effects on microleakage. Less microleakage was recorded with self-adhesive resin cement than with glass-ionomer luting cement, and CAD/CAM-fabricated $\mathrm{ZrO}_{2}$ coping showed the least marginal discrepancy and least microleakage compared with heat-pressed lithium-disilicate and cast Cr-Co.

\section{Acknowledgements}

This work was supported by Ankara University, Faculty of Dentistry, with grant number 2009/10. 


\section{References}

1. Trajtenberg CP, Caram SJ, Kiat-amnuay S. Microleakage of all-ceramic crowns using self-etching resin luting agents. Oper Dent. 2008 Jul-Aug;33(4):392-9.

2. Rossetti PHO, Valle AL, Carvalho RM, Goes MF, Pegoraro LF. Correlation between margin fit and microleakage in complete crowns cemented with three luting agents. J Appl Oral Sci. 2008 Feb;16(1):64-9.

3. Albert FE, El-Mowafy OM. Marginal adaptation and microleakage of Procera Allceram crowns with four cements. Int J Prosthodont. 2004 Sep-Oct;17(5):529-35.

4. Gorman CM, McDevitt WE, Hill RG. Comparison of two heat-pressed all-ceramic dental materials. Dent Mater. 2000 Nov;16(6):389-95.

5. Sulaiman F, Chai J, Jameson LM, Wozniak WT. A comparison of the marginal fit of In-Ceram, IPS Empress and Procera crowns. Int J Prosthodont. 1997 Sep-Oct;10(5):478-84.

6. Yeo IS, Yang JH, Lee JB. In vitro marginal fit of three allceramic crown systems. J Prosthet Dent. 2003 Nov;90(5):45964.

7. Lee K, Park C, Kim K, Kwon T. Marginal and internal fit of all-ceramic crowns fabricated with two diferent CAD/CAM systems. Dent Mater J. 2008 May;27(3):422-6.

8. Shiratsuchi H, Komine F, Kakehashi Y, Matsumura H. Influence of finish line desing on marginal adaptation of electroformed metal-ceramic crowns. J Prosthet Dent. 2006 Mar; 95(3):237-42.

9. Gu XH, Kern M. Marginal discrepancies and leakage of allceramic crowns: Influence of luting agents and aging conditions. Int J Prosthodont. 2003 Mar-Apr;16(2):109-16.

10. Lyons K M, Rodda JC, Hood JAA. Use of a pressure chamber to compare microleakage of three luting agents. Int J Prosthodont. 1997 Sep-Oct;10(5):426-33.

11. Tjan AHL, Peach KD, VanDenburgh SL, Zbaraschuk ER. Microleakage of crowns cemented with glass ionomer cemment: Effects of preparation finish and conditioning with polyacrylic acid. J Prosthet Dent. 1991 Nov;66(5):602-6.

12. Bernal G, Jones RM, Brown DT, Munoz CA, Goodacre CJ. The effect of finish line form and luting agent on the breaking strenght of Dicor crowns. Int J Prosthodont. 1993 MayJun;6(3):286-90.

13. Viotti RG, Kasaz A, Pena CE, Alexandre RS, Arrais CA, Reis AF. Microtensile bond strength of new self adhesive luting agents and conventional multistep systems. J Prosthet Dent. 2009 Nov;102(5):306-12.

14. Goldin EB, Boyd III NW, Goldstein GR, Hittelman EL, Thompson VP. Marginal fit of leucite-glass pressable ceramic restorations and ceramic-pressed-to-metal restorations. J Prosthet Dent. 2005 Feb;93(2):143-7.

15. Grey NJ, Piddock V, Wilson MA. In vitro comparison of conventional crowns and a new all-ceramic system. J Dent. 1993 Feb;21(1):47-51.

16. Gonzalo E, Suarez MJ, Serrano B, Lozano JFL. A comparison of the marginal vertical discrepancies of zirconium and metal ceramic posterior fixed dental prostheses before and after cementation. J Prosthet Dent. 2009 Dec;102(6):378-84.

17. Gonzalo E, Suarez MJ, Serrano B, Lozano JFL. Comparative analysis of two measurement methods for marginal fit in metal-ceramic and zirconia posterior FPDs. Int J Prosthodont. 2009 Jul-Aug;22(4):374-7.

18. Balkaya MC, Cinar A, Pamuk S. Influence of firing cycles on the margin distortion of 3 all-ceramic crown systems. J Prosthet Dent. 2005 Apr;93(4):346-55.

19. Ferrari M, Dagostin A, Fabianelli A. Marginal integrity of ceramic inlays luted with a self-curing resin system. Dent Mater. 2003 Jun;19(4):270-6.

20. Bönecker-Valverde G, Maniglia-Ferreira C, Abi-Rached GP, Gomes BP, Mesquita MF. Seal capability of interim post and core crown with temporary cements. Braz Oral Res. 2010 Apr-Jun;24(2):238-44.

21. Rosentritt M, Behr M, Lang R, Handel G. Influence of cement type on the marginal adaptation of all-ceramic MOD inlays. Dent Mater. 2004 Jun;20(5):463-9.

22. Reich S, Petschelt A, Lohbauer U. The effect of finish line preparation and layer thickness on the failure load and fractrography of $\mathrm{ZrO} 2$ copings. J Prosthet Dent. 2008 May;99(5):36976.

23. Hung SH, Hung KS, Eick JD, Chappell RP. Marginal fit of porcelain-fused-to metal and two types of ceramic crowns. J Prosthet Dent. 1990 Jan;63(1):26-31.

24. Beschnidt SM, Strub JR. Evaluation of the marginal accuracy of different all-ceramic crown systems after simulation in the artificial mouth. J Oral Rehabil. 1999 Jul;26(7):582-93. 